\title{
Market impacts of E. Coli vaccination in U.S. Feedlot cattle
}

\author{
Glynn T Tonsor ${ }^{*}$ and Ted C Schroeder
}

\author{
* Correspondence: gtonsor@ksu.edu \\ Department of Agriculture \\ Economics Kansas State University, \\ 342 Waters Hall, Manhattan ITS \\ 66506, USA
}

\begin{abstract}
Immunization through vaccination has been a commercially available pre-harvest intervention to reduce $E$. coli shedding in cattle for about five years. Despite demonstrated substantial improvement in human health that vaccine adoption offers, it has not been widely adopted. This highlights the need for understanding the economic situation underlying limited adoption. Using an equilibrium displacement model, this study identifies the economic impact to U.S. feedlots implementing this vaccination across a series of alternative scenarios. Producers face $\$ 1$ billion to $\$ 1.8$ billion in welfare losses over 10 years if they adopt this technology without any associated increases in demand for fed cattle. Retail beef demand increases of 1.7\% to $3.0 \%$ or export demand increases of $18.1 \%$ to $32.6 \%$ would each individually make producers economically neutral to adoption. Retail or packer cost decreases of $1.2 \%$ to $3.9 \%$ would likewise be sufficient to make producers neutral to adoption.
\end{abstract}

Keywords: Adoption incentive; Beef; Cattle; Cost savings; Demand increases; E. coli O157; Economic impacts; Food safety; Vaccination

Shiga toxin producing E. coli (STEC O157) is a serious human health hazard in the United States. STEC-related bacteria cause more than 175,000 illnesses (Scallan et al. 2011) with an annual direct economic cost ranging from $\$ 489$ million (USDA, ERS 2010 ) to $\$ 993$ million (Scharff 2010). STEC O157 is naturally occurring in cattle and, through presence in fecal material, threatens food safety if meat contamination occurs during processing.

Because of the human health threat of $E$. coli, considerable beef industry and public health official efforts have targeted pathogen reduction in beef processing plants including development of extensive hazard analysis critical control points (HACCP) and intensive testing of beef for E. coli presence (Ferrier and Buzby 2013). Pre-harvest interventions to reduce pathogens in live cattle have arisen as one strategy to lessen chances of post-harvest bacterial contamination of beef. If pathogen presence can be reduced prior to slaughter, the probability of meat contamination during carcass processing will likewise decline (Dodd et al. 2011; Hurd and Malladi 2012).

Vaccines can reduce shedding of E. coli in ruminants (Snedeker et al. 2012; Varela et al. 2013; Vogstad et al. 2013). A recently developed commercially available pre-harvest intervention to reduce E. coli shedding in cattle is immunization through vaccination (Cull et al. 2012). Despite recognition of the potential reduction in foodborne illness that could result from use of cattle E. coli vaccination, adoption is very limited (Callaway et al. 
2013; Matthews et al. 2013). Perry et al. (2007) suggest feedlot profits are not directly associated with E. coli O157:H7 prevalence as cattle feeding efficiency is not hindered. Furthermore, a well-established market that compensates producers for vaccinating for STEC 0157 has not developed. Thus, an externality exists because feedlots will not implement the socially optimal level of intervention without directly visible economic incentives. Doing so adds costs without directly visible offsetting increases in revenue. The fact that producers do not have direct incentives to employ E. coli vaccination, even though doing so would increase beef food safety, led a recent USA Today article to claim "the economics are backwards" (Weise 2011).

Despite the obvious importance to food safety and human foodborne illness, the economic feasibility and impacts of producer adoption of cattle immunization against $E$. coli have not been determined. The purpose of this study is to evaluate the economic impacts of incorporating animal vaccination into E. coli pre-harvest control practices. Specifically this study estimates direct producer costs associated with use of a vaccine in cattle feeding, referred to here as an E. coli vaccine. Direct costs include vaccine cost, costs of administering, and potential animal feeding performance impacts associated with the vaccination. Potential benefits include reduced packer or retailer costs associated with lower risk of pathogens, reduced food safety concerns, and potentially increased domestic consumer or export demand associated with safer beef. To estimate market level impacts of the vaccination, we use an equilibrium displacement model (EDM) that incorporates supply and demand shifts associated with the cattle immunization to determine economic impacts of the food safety technology across a series of alternative scenarios.

Estimating economic impacts of $E$. coli vaccines being adopted by feedlot operators is important for several reasons. First, feedlot operators need additional information to make sound adoption decisions. Secondly, understanding broader market impacts of possible adoption highlights how net benefits are distributed throughout the industry. Third, society's ongoing interest in food safety and associated desire for regular improvements in risk mitigation protocols further motivates interest from those outside the beef production chain. Given the apparent market failure of $E$. coli vaccination adoption, an assessment of economic impacts and sensitivity to various market reactions has important policy implications.

\section{Background}

Vaccination against E. coli O157:H7 and fecal shedding has been available in the United States for over five years with the first licensed vaccine approved in February 2009. The vaccine is a siderophore receptor and porin $\left(\mathrm{SRP}^{\oplus}\right)$ protein exclusively marketed by Zoetis $^{\mathrm{a}}$. The vaccine is administered to feedlot cattle during the feeding phase of production with two or three doses ${ }^{\mathrm{b}}$.

A couple of particularly noteworthy studies have examined the effectiveness of the vaccine in reducing fed cattle fecal concentrations of E. coli O157:H7 and in its impact on cattle feeding performance. Thomson et al. (2009) found use of the SRP ${ }^{\oplus}$ vaccine reduced fecal shedding concentrations in fed cattle by up to $98 \%$ and cattle feeding performance was unaffected. Cull et al. (2012) found that two doses of SRP ${ }^{\oplus}$ reduced shedding by more than $50 \%$ and reduced high shedders by more than $75 \%$. However, Cull et al. (2012) identified a small, but statistically and economically important, 
reduction in cattle feeding performance associated with vaccinating. In particular, average daily gain declined by $2.7 \%$ and feed conversion increased by $2.1 \%$ for vaccinated relative to unvaccinated cattle. The reduction in animal performance was hypothesized to be associated with the second vaccination where the vaccinated animals were processed in a chute an additional time relative to the control non-vaccinated cattle. In Thomson et al. (2009) the control cattle were vaccinated with a placebo each time, so the numbers of chute processes were the same for the control and E. coli vaccinated cattle. Running cattle through a chute can result in cattle shrink that may not be fully recaptured when placed back on feed and can temporarily disrupt cattle feed intake (Blasi et al. 2009).

Given the differences in experimental results relative to cattle feeding performance impacts associated with administration of an E. coli vaccine, we allow for alternative assumptions in our economic analyses. In particular, we consider two alternatives, one assuming no reduction in animal performance and a second assuming a $2.7 \%$ reduction in average daily gain and a $2.1 \%$ increase in feed conversion (pounds of feed per pound of gain) as a result of the vaccination.

Important to also consider are possible demand improvements or cost savings that could potentially follow implementation of $E$. coli vaccine programs at the feedlot level. Moghadam et al. (2013) estimate that E. coli O157:H7 recalls by the USDA Food Safety Inspection Service (FSIS) have a rapid and important economic impact on live cattle futures markets amounting to approximately $\$ 6 /$ head for all cattle slaughtered in the United States. Domestic beef demand has been harmed by past FSIS recall events (Marsh et al. 2004; Piggott and Marsh 2004; Tonsor et al. 2010). Furthermore, export market demand for U.S. beef is highly sensitive to food safety (Bailey 2007). As such, domestic retail beef demand and wholesale export beef demand could improve with $E$. coli vaccine programs that reduce $E$. coli prevalence.

Extensive research has examined the cost impacts of additional food safety programs and protocols being introduced into the U.S. beef industry (Antle 1999; 2000). Costs include direct production costs such as additional labor requirements, slowing down processing line speed, investing in food safety technologies, modifying processing procedures or facilities, and expenses of more intensive product sampling and food safety testing (Ferrier and Buzby 2013). In face of a recall, costs of plant down-time, clean up, physical product losses, costs of completing a food recall, and loss of firm customers and reputation can collectively be substantial. Important expenses also include possible litigation costs associated with foodborne human illnesses that have proved expensive in cases where meat food safety breaches have occurred (e.g., Gabbett 2010; Scott 2012).

Given the sizeable costs involved to downstream firms in light of a food safety event, substantial incentives are present to reduce the probabilities of such events including the possibility of feedlots implementing E. coli vaccine programs. In essence, use of an E. coli vaccine by cattle producers could result in notable benefits to downstream firms but direct benefits to producers that incur the costs of adoption are currently elusive, limiting adoption.

Given the economic importance of identifying the economic impact E. coli vaccine program introduction could have on stakeholders throughout the meat and livestock chain we first directly estimate market impacts in the absence of incentivizing demand improvements or possible downstream cost savings. Given the unknown nature of possible demand or cost improvements we then proceed to estimate market impacts 
under alternative market scenarios to identify the specific beef demand improvements or cost savings that would be needed to make feedlot operators in aggregate indifferent to adoption.

Estimating and discussing these demand or cost improvements that may lead to feedlot adoption is important for several reasons. First, as the levels of demand or cost adjustments that could be experienced elsewhere in the supply chain are realized, having critical thresholds identified is valuable. Second, cattle producers would adopt vaccine programs if they received offsetting benefits which reinforces the value in identifying necessary demand or cost improvements further upstream to encourage adoption (Smith et al. 2013). Finally, from a policy perspective, any cost-benefit analysis of alternative beef food safety enhancing interventions requires the information provided in this study regarding market impacts of these interventions.

\section{Methods}

The methodological approach can succinctly be described as using estimates of costs increases incurred by feedlots implementing $E$. coli vaccination programs and estimating changes in prices and quantities at market levels spanning the vertically linked beef industry as well as connected pork and poultry markets. The initial exogenous market shock is feedlot level production costs increasing leading to an inward shift in fed cattle supply. To estimate the market level impact of $E$. coli vaccination on prices and quantities throughout the livestock and meat industry we employ an equilibrium displacement model (EDM). The EDM utilized here is similar to that used by Schroeder and Tonsor (2011) and is documented in the appendix.

The EDM is composed of four sectors in the beef industry: 1) retail (consumer), 2) wholesale (processor/packer), 3) fed cattle (cattle feeding in feedlots), and 4) farm (feeder cattle from cow-calf producers). To capture interactions between retail meat substitutes for beef we also include the pork and poultry markets. Reflecting the higher degree of integration relative to the beef industry, the economic model includes three pork marketing chain sectors (retail, wholesale, and fed cattle) and the poultry marketing chain is composed of two sectors (retail and wholesale). International trade is explicitly incorporated in the model at the wholesale level for all three species. The resulting framework is consistent with existing research and follows the recent work of Brester et al. (2004) and Pendell et al. (2010).

Given estimated changes in prices and quantities, producer surplus at the feedlot level where the adoption decision occurs, as well as other levels in the vertically linked supply chain, is calculated as a widely accepted measure of economic welfare impact. As in most EDM applications, direct estimation of elasticities is prohibitive because of the large number of equations and identification problems in jointly estimating supply and demand relationships (Brester et al. 2004). However, given the E. coli vaccination results in relatively small aggregate market shifts (in proportional terms), we follow standard EDM procedures and utilize elasticity estimates reported in the published literature to parameterize the model.

We simulate our model annually for ten consecutive years to trace a hypothetical adoption path over time by producers of the E. coli vaccination technology. Consistent with historical beef cattle cycles, we assume it takes the marketplace ten years to fully adjust from short-run to long-run relationships. Ten years of market effects were 
simulated by linearly adjusting all elasticities between short-run (year 1) and long-run (year 10) using elasticity estimates employed by Pendell et al. (2010) ${ }^{\mathrm{c}}$. Supply, demand, and quantity transmission elasticities used are equivalent to those used by Schroeder and Tonsor (2011). Similarly, base price and quantity values are necessary to estimate surplus calculations. The market price and quantity values are annual averages for calendar year 2012 as reported by the Livestock Marketing Information Center (LMIC).

Our analysis assumes $10 \%$ of fed cattle are vaccinated in year 1, 25\% in year 2, 50\% in year 3, and $90 \%$ in years $4-10$. This reflects a typical "S-curve" adoption pattern where adoption increases rapidly upon introduction of the technology with a plateau corresponding to the fact that few technologies are ever completely adopted by all parties in a heterogeneous industry. The employed adoption rate would of course only occur if private market incentives to adopt were widely present and accessible to producers, which currently they are not. As such, the adoption rate is used here for exemplification and estimation of cost impacts and is not a forecast of a probable adoption path given current market conditions.

\section{Results}

When feedlot operators implement $E$. coli vaccination protocols one main direct impact serves as the initial shock in our EDM. Specifically, production costs increase leading to an inward shift in fed cattle supply. This initial exogenous shock initiates a ripple-effect through the industry as reflected in multiple endogenous shifts outlined within the EDM.

The change in net returns of finishing cattle for those implementing E. coli vaccinations were calculated under alternative assumptions following Lueger et al. (2012). When assuming no animal performance impact, the direct costs are estimated at $\$ 6.47 /$ head with the vaccination being administered twice to each animal. The first vaccination occurs upon arrival at the feedlot where cattle are all processed through a chute anyway (so no additional chute charge or animal processing is associated uniquely to the $E$. coli vaccination). For the second vaccination, additional chute and labor charges occur since cattle would not generally be processed through the chute again unless being vaccinated for E. coli. One potentially important addition to the direct costs of vaccinating is whether an adverse animal performance outcome occurs from the vaccination. Research includes no impact (Thomson et al. 2009) to an observed animal performance decline (Cull et al. 2012). As such, a second cost scenario is assumed where the direct costs that include vaccination and animal performance losses are estimated at $\$ 13.11 /$ head (Lueger et al. 2012). In addition to these base direct costs, adopting feedyards could incur costs associated with third-party verification that $E$. coli vaccinations were indeed implemented if packers were going to pay them for such a verified production protocol. We assume $E$. coli vaccination verification costs of $\$ 1.88 /$ head which are based on costs for age and source verification identified by Pendell et al. (2013).

Given the magnitude of the direct costs for feedlots to vaccinate, they generally will not without a clear direct economic incentive. As such, determining the downstream benefits that would need to occur to encourage adoption is essential to understand if adoption is desirable. The $\$ /$ head implementation costs are presented in Table 1 along with the exogenous supply shifts these cost increases represent in each year within the EDM given an average fed cattle value in 2012 of $\$ 1,604 /$ head. 
Table 1 Exogenous fed cattle production cost increase of vaccination and verification program adoption

\begin{tabular}{llllll}
\hline \multirow{2}{*}{ Scenario: } & \multicolumn{4}{l}{ Percentage inward supply shift } \\
\cline { 2 - 6 } & Direct & Year $\mathbf{1}$ & Year $\mathbf{2}$ & Year 3 & Years 4-10 \\
& Cost & $\mathbf{1 0 \%}$ & $\mathbf{2 5 \%}$ & $\mathbf{5 0 \%}$ & $\mathbf{9 0 \%}$ \\
& $\mathbf{\$} \mathbf{h d}^{\mathbf{a}}$ & Adoption & Adoption & Adoption & Adoption \\
\hline No animal performance impact & $\$ 8.35$ & $0.052 \%$ & $0.130 \%$ & $0.260 \%$ & $0.468 \%$ \\
Animal performance impact & $\$ 14.99$ & $0.093 \%$ & $0.234 \%$ & $0.467 \%$ & $0.841 \%$ \\
\hline
\end{tabular}

${ }^{\mathrm{a}}$ Includes $\$ 6.47$ per head cost of vaccinating plus $\$ 1.88$ per head verification cost under no animal performance impact and $\$ 13.11$ per head cost under performance impact plus $\$ 1.88$ per head verification cost.

The EDM was first applied to identify economic impacts in the case of $E$. coli vaccination program implementation without additional demand or cost benefits occurring elsewhere in the supply chain. This scenario of course would not happen because feedlots will not adopt without clear direct benefits. But having this scenario is necessary to determine the subsequent magnitudes of market events that would need to occur to entice adoption.

Table 2 summarizes the short- (1-year), intermediate- (5-year), and long-run (10-year) changes in prices and quantities estimated by the EDM where animal performance impacts are omitted and considered. Retail and wholesale beef as well as fed cattle, and feeder cattle quantities all decline in each of the 10 years considered. The reduced production volumes reflect the inward shift in fed cattle supply, derived inward shifts in wholesale and retail beef supplies, and derived demand reductions experienced at the feeder cattle level following the increased production costs for feedlots. Retail and wholesale beef prices increase in all 10 years as the increased feedlot costs pass vertically towards consumers. Feeder cattle prices decline in all 10 years as feedlot vaccination costs reduce derived demand for feeder cattle. The fed cattle price path switches signs over the 10 years examined. Specifically, fed cattle prices decline in years 1 and 2 and increase over years 3-10 reflecting long-run supply being more elastic than shortrun supply and a multitude of derived demand and supply feedbacks captured by the model. The quantities of wholesale beef exported and imported, as well as the price of imported wholesale beef all decline over the 10 years evaluated. This primarily follows an overall reduction in wholesale beef supplies and increased wholesale beef prices. More broadly, the long-run impacts are smaller as the entire supply chain adjusts to E. coli vaccination program implementation over time.

In the base situation of no additional demand enhancement or cost savings, the cumulative net present value producer surplus losses over ten years at the feedlot level are $\$ 1.00$ billion if no animal performance reduction occurred by vaccinating and $\$ 1.79$ billion if reduced animal performance is considered (Table 3). This substantial difference in welfare, despite small potential impacts on animal performance, clearly illustrates how the economic value of interventions changes if animal productivity is affected.

These substantial losses reflect changes in prices and quantities summarized in Table 2 and occur if the adoption rate we assume and no offsetting benefits materialize. This illustrates why, consistent with Matthews et al. (2013) and Callaway et al. (2013), limited voluntary adoption of $E$. coli vaccination will occur unless recognized direct incentives for implementation arise. Such incentives could occur in the form of derived demand increasing for fed cattle from feedlots with $E$. coli vaccination programs if either domestic retail or wholesale export beef demand increased following program 
Table 2 Percentage change in endogenous variables of the equilibrium displacement models with adoption costs but no benefits scenario

\begin{tabular}{|c|c|c|c|c|c|c|}
\hline \multirow[b]{2}{*}{ Endogenous variables } & \multicolumn{3}{|c|}{ No animal performance impact } & \multicolumn{3}{|c|}{ With animal performance impact } \\
\hline & Short run & Intermediate & Long run & Short run & Intermediate & Long run \\
\hline Retail beef quantity & $-0.27 \%$ & $-0.04 \%$ & $-0.01 \%$ & $-0.49 \%$ & $-0.06 \%$ & $-0.01 \%$ \\
\hline Retail beef price & $0.32 \%$ & $0.04 \%$ & $0.01 \%$ & $0.58 \%$ & $0.06 \%$ & $0.01 \%$ \\
\hline Wholesale beef quantity & $-0.51 \%$ & $-0.15 \%$ & $-0.04 \%$ & $-0.91 \%$ & $-0.27 \%$ & $-0.07 \%$ \\
\hline Wholesale beef price & $0.40 \%$ & $0.16 \%$ & $0.04 \%$ & $0.72 \%$ & $0.28 \%$ & $0.07 \%$ \\
\hline Slaughter cattle quantity & $-0.40 \%$ & $-0.28 \%$ & $-0.12 \%$ & $-0.72 \%$ & $-0.51 \%$ & $-0.21 \%$ \\
\hline Slaughter cattle price & $-0.38 \%$ & $0.26 \%$ & $0.14 \%$ & $-0.68 \%$ & $0.46 \%$ & $0.25 \%$ \\
\hline Feeder cattle quantity & $-0.23 \%$ & $-0.21 \%$ & $-0.09 \%$ & $-0.42 \%$ & $-0.37 \%$ & $-0.16 \%$ \\
\hline Feeder cattle price & $-1.06 \%$ & $-0.15 \%$ & $-0.03 \%$ & $-1.91 \%$ & $-0.27 \%$ & $-0.06 \%$ \\
\hline Imported wholesale beef quantity & $-0.38 \%$ & $-0.13 \%$ & $-0.04 \%$ & $-0.69 \%$ & $-0.24 \%$ & $-0.07 \%$ \\
\hline Exported wholesale beef quantity & $-0.17 \%$ & $-0.24 \%$ & $-0.11 \%$ & $-0.30 \%$ & $-0.44 \%$ & $-0.20 \%$ \\
\hline Imported wholesale beef price & $-0.21 \%$ & $-0.02 \%$ & $0.00 \%$ & $-0.37 \%$ & $-0.04 \%$ & $-0.01 \%$ \\
\hline Retail pork quantity & $0.04 \%$ & $0.01 \%$ & $0.00 \%$ & $0.08 \%$ & $0.01 \%$ & $0.00 \%$ \\
\hline Retail pork price & $0.02 \%$ & $0.00 \%$ & $0.00 \%$ & $0.04 \%$ & $0.00 \%$ & $0.00 \%$ \\
\hline Wholesale pork quantity & $0.03 \%$ & $0.01 \%$ & $0.00 \%$ & $0.05 \%$ & $0.01 \%$ & $0.00 \%$ \\
\hline Wholesale pork price & $0.02 \%$ & $0.00 \%$ & $0.00 \%$ & $0.03 \%$ & $0.00 \%$ & $0.00 \%$ \\
\hline Slaughter hogs quantity & $0.01 \%$ & $0.00 \%$ & $0.00 \%$ & $0.02 \%$ & $0.01 \%$ & $0.00 \%$ \\
\hline Slaughter hogs price & $0.03 \%$ & $0.00 \%$ & $0.00 \%$ & $0.06 \%$ & $0.01 \%$ & $0.00 \%$ \\
\hline Imported wholesale pork quantity & $0.02 \%$ & $0.00 \%$ & $0.00 \%$ & $0.03 \%$ & $0.01 \%$ & $0.00 \%$ \\
\hline Exported wholesale pork quantity & $-0.02 \%$ & $0.00 \%$ & $0.00 \%$ & $-0.03 \%$ & $0.00 \%$ & $0.00 \%$ \\
\hline Imported wholesale pork price & $0.01 \%$ & $0.00 \%$ & $0.00 \%$ & $0.02 \%$ & $0.00 \%$ & $0.00 \%$ \\
\hline Retail poultry quantity & $0.05 \%$ & $0.01 \%$ & $0.00 \%$ & $0.08 \%$ & $0.01 \%$ & $0.00 \%$ \\
\hline Retail poultry price & $0.04 \%$ & $0.00 \%$ & $0.00 \%$ & $0.08 \%$ & $0.00 \%$ & $0.00 \%$ \\
\hline Wholesale poultry quantity & $0.05 \%$ & $0.01 \%$ & $0.00 \%$ & $0.09 \%$ & $0.01 \%$ & $0.00 \%$ \\
\hline Wholesale poultry price & $0.00 \%$ & $0.00 \%$ & $0.00 \%$ & $0.00 \%$ & $0.00 \%$ & $0.00 \%$ \\
\hline Exported wholesale poultry quantity & $-0.32 \%$ & $-0.04 \%$ & $-0.01 \%$ & $-0.57 \%$ & $-0.08 \%$ & $-0.01 \%$ \\
\hline
\end{tabular}

Note: These percentage changes are relative to $0 \%$ vaccination and verification adoption. Short-, intermediate-, and long-run corresponds to years 1,5 , and 10, respectively from the EDM simulated over 10 consecutive years. Percentage changes for each individual year are available upon request.

implementation. Similarly, a derived demand benefit could materialize if production costs at either the retail or wholesale level declined following E. coli vaccination program implementation. Given these unknown but important plausible alternatives, we extended our analysis and utilized the EDM to identify demand benefits or cost savings needed to make the feedlot level indifferent to adoption.

Table 4 presents the estimated retail demand increase, wholesale export demand increase, retail cost savings, and wholesale costs savings that result in no changes in producer surplus at the fed cattle (feedlot) level ${ }^{\mathrm{d}}$. Note, the estimates in Table 4 are for independent downstream shocks to demand or costs needed to make feedlot producers economically indifferent to adoption. Possible combinations of demand and cost impacts would be smaller than individual shocks necessary to make feedlot producers indifferent. The minimum changes that may lead to feedlot adoption are lower in each case where implementing an E. coli vaccination program does not impact animal performance. 
Table 3 Producer surplus changes from vaccination and verification program adoption (\$ millions), no benefits scenario

\begin{tabular}{|c|c|c|c|c|c|c|c|c|}
\hline \multirow[b]{2}{*}{ Beef producer surplus } & \multicolumn{4}{|c|}{ No animal performance impact } & \multicolumn{4}{|c|}{ With animal performance impact } \\
\hline & Short run & Intermediate run & Long run & Cumulative present value & Short run & Intermediate run & Long run & Cumulative present value \\
\hline Retail level & 294.05 & 32.58 & 5.07 & 654.66 & 527.41 & 58.49 & 9.10 & $1,174.59$ \\
\hline Wholesale level & 197.81 & 76.67 & 18.49 & 804.03 & 354.46 & 137.58 & 33.20 & $1,441.69$ \\
\hline Fed cattle level & -224.72 & -110.56 & -173.92 & $-1,000.90$ & -402.86 & -198.29 & -312.13 & $-1,795.23$ \\
\hline Feeder cattle level & -434.83 & -61.77 & -12.98 & $-1,018.27$ & -780.04 & -110.82 & -23.30 & $-1,826.42$ \\
\hline Total Beef Industry Producer Surplus & -167.69 & -63.08 & -163.33 & -560.48 & -301.02 & -113.04 & -293.13 & $-1,005.37$ \\
\hline
\end{tabular}

Note: Producer surplus is calculated relative to 2012 quantities and prices for livestock and meat. Cumulative net present value was calculated using a 5\% discount rate. 
Table 4 Independent changes needed for no change in feedlot sector producer surplus

\begin{tabular}{lll}
\hline & $\begin{array}{l}\text { No animal performance } \\
\text { impact }\end{array}$ & $\begin{array}{l}\text { With animal performance } \\
\text { impact }\end{array}$ \\
\hline Domestic retail beef demand increase & $1.7 \%$ & $3.0 \%$ \\
Wholesale export beef demand increase & $18.1 \%$ & $32.6 \%$ \\
Retail beef (retailer) cost decrease & $2.2 \%$ & $3.9 \%$ \\
Wholesale beef (packer) cost decrease & $1.2 \%$ & $2.2 \%$ \\
\hline $\begin{array}{l}\text { Note: Values are the exogenous responses (demand increases or cost savings) resulting in cumulative net present value } \\
\text { of producer surplus not changing at the fed cattle level (feedlots). Demand increases on all beef production were }\end{array}$ \\
$\begin{array}{l}\text { considered while cost savings evaluated corresponded only to the portion of product retailers or packers would receive } \\
\text { from E. coli vaccination programs reflecting the 10-year adoption path assumed. }\end{array}$
\end{tabular}

When animal performance impacts are considered, either a 3.0\% increase in domestic retail beef demand or a $32.6 \%$ increase in wholesale export beef demand would provide the derived demand benefits to make feedlot operators indifferent to implementation. The 3.0\% domestic retail demand increase is within the range of experienced annual demand shifts in the U.S. (AgManager 2013). However, the finding of Zingg and Siegrist (2012) that a minority of consumers may be willing to consume meat from vaccinated animals casts some doubt on the extent of a positive, aggregate retail demand response. In 2012 Japan and South Korea combined accounted for 30.8\% of total U.S. beef exports (LMIC 2013). Accordingly, context on the $32.6 \%$ wholesale export increase can readily be made noting how maintaining access to Japan and South Korea by avoiding food-safety related market closures could offset feedlot level vaccination program costs. The identification of thresholds for export demand increases being approximately 10 times those of domestic demand increases reflects the fact approximately $90 \%$ of beef produced in the U.S. is consumed domestically. While domestic and export demand responses are unknown, recognizing the demand response thresholds is important for broader industrywide deliberations and sets the stage for additional future research.

Table 4 also indicates that $3.9 \%(2.2 \%)$ cost savings for retailers or $2.2 \%(1.2 \%)$ cost savings for packers results in no net economic welfare changes for the feedlot segment if animal productivity is (not) reduced through a vaccination protocol. As with the threshold demand values, the precise level of cost savings at retail or wholesale levels are unknown as adjustments that operations may make in E. coli mitigation efforts have yet to be directly studied. Hurd and Malladi (2012) concluded that the number of ground beef-related E. coli human illnesses in the United States could be reduced by $58 \%$ from about 20,000 illnesses to around 8,400 per year under an $80 \%$ effective and fully adopted feedlot steer and heifer vaccination program. Smith et al. (2013) found combinations of interventions applied pre-harvest and throughout processing resulted in larger relative E. coli risk reductions. If a single and relatively simple intervention such as a vaccination program would have this dramatic of impact on foodborne illnesses, downstream cost savings would certainly be realized. Estimating potential downstream cost savings is an area ripe for future research.

\section{Discussion and Conclusions}

This study expands knowledge of economic implications of implementing E. coli vaccination programs, highlights key areas of where additional research would be valuable, and provides information that could improve societal response to efficiently mitigating food safety risks. Vaccinations by feedlots could potentially reduce $E$. coli 
related human foodborne illnesses from ground-beef by 58\% (Hurd and Malladi 2012). However, cattle producers will not adopt E. coli vaccination programs without offsetting direct benefits because doing so is costly and would reduce their economic welfare by $\$ 1$ billion to $\$ 1.8$ billion. Currently, direct benefits of $E$. coli vaccine adoption by cattle producers are elusive as a well-established market premium does not exist despite the vaccine having been commercially available for over five years now.

What might it take for $E$. coli vaccination programs to be successfully implemented? We illustrate the threshold magnitudes of downstream demand improvements or cost savings that are needed to provide producers economic incentives to adopt $E$. coli vaccination programs. Domestic consumer demand increases of 2-3\%, export wholesale market increases of $18-33 \%$, retailer cost reductions of $2-4 \%$, or processor cost reductions of $1-2 \%$ would each individually be sufficient to make producer adoption welfare neutral.

This study also highlights the need to further examine if human health benefits from implementing E. coli vaccination programs are significant enough to consider additional policy adjustments that encourage adoption. This issue is beyond the economics of adoption focused scope of this paper but certainly is an area of importance for future research. Similarly, a valuable area for future research is to consider the demand increase and cost reduction thresholds identified in this study and determine whether and how $E$. coli vaccination adoption incentives might occur and translate incentives back to cattle producers.

\section{Endnotes}

${ }^{a}$ See: https://online.zoetis.com/US/EN/Solutions/Pages/SRPEcoli/index.aspx

${ }^{b}$ Experiments with both two doses and three doses have been conducted (Cull et al. 2012; Thomson et al. 2009) with three doses showing a trend in efficacy.

${ }^{c}$ Available at: http://ajae.oxfordjournals.org/content/suppl/2010/04/29/aaq037.DC1/ aaq037supp.pdf

${ }^{\mathrm{d}}$ Demand increases were modelled to impact $100 \%$ of production over the 10 year period while cost increases were modelled to impact only the portion of production that aligns with feedlot vaccination adoption. That is, demand increases reflect an assumption of product being undifferentiated downstream to buyers while cost increases reflect an assumption of downstream purchases only experiencing cost savings when product is verified to be sourced from adopting feedyards.

${ }^{\text {e}}$ This model follows Pendell et al. (2010) and similar studies in assuming international trade can be succinctly captured by including exchange of meat products while not explicitly incorporating live animal trade.

${ }^{\mathrm{f}}$ Available at: http://ajae.oxfordjournals.org/content/suppl/2010/04/29/aaq037.DC1/ aaq037supp.pdf

\section{APPENDIX - Details of Applied Equilibrium Displacement Model}

To estimate the market level impact of $E$. coli vaccination we employ an equilibrium displacement model (EDM). The EDM utilized here is similar to that used by Schroeder and Tonsor (2011). The EDM is composed of four sectors in the beef industry: 1) retail (consumer), 2) wholesale (processor/packer), 3) fed cattle (cattle feeding in feedlots), and 4) farm (feeder cattle from cow-calf producers). To capture interactions between retail meat substitutes for beef we also include the pork and poultry markets. Reflecting the 
higher degree of integration relative to the beef industry, the economic model includes three pork marketing chain sectors (retail, wholesale, and fed cattle) and the poultry marketing chain is composed of two sectors (retail and wholesale). International trade is explicitly incorporated in the model at the wholesale level for all three species. The resulting framework is consistent with existing research and most closely follows the recent work of Brester et al. (2004) and Pendell et al. (2010). The structural model (omitting error terms for convenience) is given by the following series of general demand and supply equations of this multi-species model. Superscripts $r, w, s$, and $f$ denote the retail, wholesale, fed cattle, and farm market levels, respectively; subscripts $B, K$, and $Y$ denote beef, pork, and poultry, respectively; $P$ is price; $Q$ is quantity; and $Z$ and $W$ denote demand and supply shifters, respectively. Consistent with existing international trade, the model captures imports (subscript $i$ ) and exports (subscript $e$ ) of beef, pork, and poultry ${ }^{\mathrm{e}}$. Equations (1) - (25) omit superscripts for demand and supply as market clearing conditions are imposed, requiring demand and supply to equal.

\section{Beef marketing chain}

(1) Retail beef primary demand: $Q_{B}^{r}=f_{1}\left(P_{B}^{r}, P_{K}^{r}, P_{Y}^{r}, Z_{B}^{r}\right)$,

(2) Retail beef derived supply: $Q_{B}^{r}=f_{2}\left(P_{B}^{r}, Q_{B}^{w}, W_{B}^{r}\right)$,

(3) Wholesale beef derived demand: $Q_{B}^{w}=f_{3}\left(P_{B}^{w}, Q_{B}^{r}, Z_{B}^{w}\right)$,

(4) Wholesale beef derived supply: $Q_{B}^{w}=f_{4}\left(P_{B}^{w}, Q_{B}^{s}, Q_{B i}^{w}, Q_{B e}^{w}, W_{B}^{w}\right)$,

(5)Imported wholesale beef derived demand: $Q_{B i}^{w}=f_{5}\left(P_{B i}^{w}, Q_{B}^{w}, Z_{B i}^{w}\right)$,

(6) Imported wholesale beef derived supply: $Q_{B i}^{w}=f_{6}\left(P_{B i}^{w}, W_{B i}^{w}\right)$,

(7) Exported wholesale beef derived demand: $Q_{B e}^{w}=f_{7}\left(P_{B}^{w}, Z_{B e}^{w}\right)$,

(8)Fed cattle derived demand: $Q_{B}^{s}=f_{8}\left(P_{B}^{s}, Q_{B}^{w}, Z_{B}^{s}\right)$,

(9) Fed cattle derived supply: $Q_{B}^{s}=f_{9}\left(P_{B}^{s}, Q_{B}^{f}, W_{B}^{s}\right)$,

(10) Farm (feeder cattle) derived demand: $Q_{B}^{f}=f_{10}\left(P_{B}^{f}, Q_{B}^{s}, Z_{B}^{f}\right)$,

(11) Farm (feeder cattle) primary supply: $Q_{B}^{f}=f_{11}\left(P_{B}^{f}, W_{B}^{f}\right)$,

\section{Pork marketing chain}

(12) Retail pork primary demand: $Q_{K}^{r}=f_{12}\left(P_{B}^{r}, P_{K}^{r}, P_{Y}^{r}, Z_{K}^{r}\right)$,

(13) Retail pork derived supply: $Q_{K}^{r}=f_{13}\left(P_{K}^{r}, Q_{K}^{w}, W_{K}^{r}\right)$,

(14) Wholesale pork derived demand: $Q_{K}^{w}=f_{14}\left(P_{K}^{w}, Q_{K}^{r}, Z_{K}^{w}\right)$,

(15) Wholesale pork derived supply: $Q_{K}^{w}=f_{15}\left(P_{K}^{w}, Q_{K}^{s}, Q_{K i}^{w}, Q_{K e}^{w}, W_{B}^{w}\right)$,

(16) Imported wholesale pork derived demand: $Q_{K i}^{w}=f_{16}\left(P_{K i}^{w}, Q_{K}^{w}, Z_{K i}^{w}\right)$,

(17) Imported wholesale pork derived supply: $Q_{K i}^{w}=f_{17}\left(P_{K i}^{w}, W_{K i}^{w}\right)$,

(18) Exported wholesale pork derived demand: $Q_{K e}^{w}=f_{18}\left(P_{K}^{w}, Z_{K e}^{w}\right)$,

(19) Market hog derived demand: $Q_{K}^{s}=f_{19}\left(P_{K}^{s}, Q_{K}^{w}, Z_{K}^{s}\right)$,

(20) Market hog primary supply: $Q_{K}^{s}=f_{20}\left(P_{K}^{s}, W_{K}^{s}\right)$,

\section{Poultry marketing chain}

(21) Retail poultry primary demand: $Q_{Y}^{r}=f_{21}\left(P_{B}^{r}, P_{K}^{r}, P_{Y}^{r}, Z_{Y}^{r}\right)$,

(22) Retail poultry derived supply: $Q_{Y}^{r}=f_{22}\left(P_{Y}^{r}, Q_{Y}^{w}, Q_{Y e}^{r}, W_{Y}^{r}\right)$,

(23) Wholesale poultry derived demand: $Q_{Y}^{w}=f_{23}\left(P_{Y}^{w}, Q_{Y}^{r}, Z_{Y}^{w}\right)$, 
(24) Wholesale poultry primary supply: $Q_{Y}^{w}=f_{24}\left(P_{Y}^{w}, W_{Y}^{w}\right)$,

(25) Exported wholesale poultry derived demand: $Q_{Y e}^{w}=f_{25}\left(P_{Y}^{w}, Z_{Y e}^{w}\right)$.

Consistent with Wohlgenant (1993), we incorporate variable input proportions by allowing production quantities to vary across the market levels in the marketing chain. Totally differentiating equations (1) - (25), including variable input proportions, and placing all the endogenous variables on the left-hand side of each equation and isolating exogenous effects to the right-hand side of each equation results in the following EDM. $E$ represents a relative change operator (i.e., $E Q=d \ln Q=d Q / Q$ ); $\eta_{a}^{m}$ is the own-price elasticity of meat/species $a$ demand at market level $m ; \eta_{a b}^{m}$ is the cross-price elasticity of demand for meat $a$ with respect to retail prices of meat $b ; \varepsilon_{a}^{m}$ is the own-price elasticity of meat/species a supply at market level $m ; \tau^{l m}$ is the percentage change in quantity demanded at market level $m$ given a $1 \%$ change in quantity demanded at market level $l$; $\gamma^{I m}$ is the percentage change in quantity supplied at market level $m$ given a $1 \%$ change in quantity supplied at market level $l$. In this specification, market levels are linked by downstream quantity variables among the demand equations and upstream quantity variables among the supply equations (Wohlgenant 1993).

\section{Beef marketing chain}

(1") Retail beef primary demand: $E Q_{B}^{r}-\eta_{B}^{r} E P_{B}^{r}-\eta_{B K}^{r} E P_{K}^{r}-\eta_{B Y}^{r} E P_{Y}^{r}=E Z_{B}^{r}$,

(2") Retail beef derived supply: $E Q_{B}^{r}-\varepsilon_{B}^{r} E P_{B}^{r}-\gamma_{B}^{w r} E Q_{B}^{w}=E W_{B}^{r}$,

(3") Wholesale beef derived demand: $E Q_{B}^{w}-\eta_{B}^{w} E P_{B}^{w}-\tau_{B}^{r w} E Q_{B}^{r}=E Z_{B}^{w}$,

$(4 ")$ Wholesale beef derived supply:

$$
E Q_{B}^{w}-\varepsilon_{B}^{w} E P_{B}^{w}-\gamma_{B}^{s w}\left(Q_{B}^{s} / Q_{B}^{w}\right) E Q_{B}^{s}-\left(Q_{B i}^{w} / Q_{B}^{w}\right) E Q_{B i}^{w}+\left(Q_{B e}^{w} / Q_{B}^{w}\right) E Q_{B e}^{w}=E W_{B}^{w},
$$

(5") Imported wholesale beef derived demand: $E Q_{B i}^{w}-\eta_{B i}^{w} E P_{B i}^{w}-\tau_{B}^{r w} E Q_{B}^{w}=\left(Q_{B i}^{w} / Q_{B}^{w}\right)$ $E Z_{B e}^{w}+E Z_{B i}^{w}$,

(6") Imported wholesale beef derived supply: $E Q_{B i}^{w}-\varepsilon_{B i}^{w} E P_{B i}^{w}=E W_{B i}^{w}$,

(7") Exported wholesale beef derived demand: $E Q_{B e}^{w}-\eta_{B e}^{w} E P_{B}^{w}=E Z_{B e}^{w}$,

(8") Fed cattle derived demand: $E Q_{B}^{s}-\eta_{B}^{s} E P_{B}^{s}-\tau_{B}^{w s} E Q_{B}^{w}=\left(Q_{B e}^{w} / Q_{B}^{w}\right) E Z_{B e}^{w}+E Z_{B}^{s}$,

(9") Fed cattle derived supply: $E Q_{B}^{s}-\varepsilon_{B}^{s} E P_{B}^{s}-\gamma_{B}^{f_{s}} E Q_{B}^{f}=E W_{B}^{s}$,

$\left(10^{\prime \prime}\right)$ Farm (feeder cattle) derived demand: $E Q_{B}^{f}-\eta_{B}^{f} E P_{B}^{f}-\tau_{B}^{s f} E Q_{B}^{s}=E Z_{B}^{f}$,

$\left(11^{\prime \prime}\right)$ Farm (feeder cattle) primary supply: $E Q_{B}^{f}-\varepsilon_{B}^{f} E P_{B}^{f}=E W_{B}^{f}$,

\section{Pork marketing chain}

(12") Retail pork primary demand: $E Q_{K}^{r}-\eta_{K B}^{r} E P_{B}^{r}-\eta_{K}^{r} E P_{K}^{r}-\eta_{K Y}^{r} E P_{Y}^{r}=E Z_{K}^{r}$,

(13") Retail pork derived supply: $E Q_{K}^{r}-\varepsilon_{K}^{r} E P_{K}^{r}-\gamma_{K}^{w r} E Q_{K}^{w}=E W_{K}^{r}$,

(14") Wholesale pork derived demand: $E Q_{K}^{w}-\eta_{K}^{w} E P_{K}^{w}-\tau_{K}^{r w} E Q_{K}^{r}=E Z_{K}^{w}$,

(15") Wholesale pork derived supply: $E Q_{K}^{w}-\varepsilon_{K}^{w} E P_{K}^{w}-\gamma_{K}^{s w}\left(Q_{K}^{s} / Q_{K}^{w}\right) E Q_{K}^{s}-\left(Q_{K i}^{w} / Q_{K}^{w}\right) E Q_{K i}^{w}+$ $\left(Q_{K e}^{w} / Q_{K}^{w}\right) E Q_{K e}^{w}=E W_{K}^{w}$,

(16") Imported wholesale pork derived demand: $E Q_{K i}^{w}-\eta_{K i}^{w} E P_{K i}^{w}-\tau_{K}^{r w} E Q_{K}^{w}=\left(Q_{K i}^{w} / Q_{K}^{w}\right)$ $E Z_{K e}^{w}+E Z_{K i}^{w}$,

$\left(17^{\prime \prime}\right)$ Imported wholesale pork derived supply: $E Q_{K i}^{w}-\varepsilon_{K i}^{w} E P_{K i}^{w}=E W_{K i}^{w}$,

$\left(18^{\prime \prime}\right)$ Exported wholesale pork derived demand: $E Q_{K e}^{w}-\eta_{K e}^{w} E P_{K}^{w}=E Z_{K e}^{w}$, 
(19") Market hog derived demand: $E Q_{K}^{s}-\eta_{K}^{s} E P_{K}^{s}-\tau_{K}^{w s} E Q_{K}^{w}=\left(Q_{K e}^{w} / Q_{K}^{w}\right) E Z_{K e}^{w}+E Z_{K}^{s}$,

(20") Market hog primary supply: $E Q_{K}^{s}-\varepsilon_{K}^{s} E P_{K}^{s}=E W_{K}^{s}$,

\section{Poultry marketing chain}

(21") Retail poultry primary demand: $E Q_{Y}^{r}-\eta_{Y B}^{r} E P_{B}^{r}-\eta_{Y K}^{r} E P_{K}^{r}-\eta_{Y}^{r} E P_{Y}^{r}=E Z_{Y}^{r}$,

(22") Retail poultry derived supply: $E Q_{Y}^{r}-\varepsilon_{Y}^{r} E P_{Y}^{r}-\gamma_{Y}^{w r} E Q_{Y}^{w}=E W_{Y}^{r}$,

(23") Wholesale poultry derived demand: $E Q_{Y}^{w}-\eta_{Y}^{w} E P_{Y}^{w}-\tau_{Y}^{r w} E Q_{Y}^{r}=E Z_{Y}^{w}$,

(24") Wholesale poultry primary supply: $E Q_{Y}^{w}-\varepsilon_{Y}^{w} E P_{Y}^{w}+\left(Q_{Y e}^{w} / Q_{Y}^{w}\right) E Q_{Y e}^{w}=E W_{Y}^{w}$,

$\left(25^{\prime \prime}\right)$ Exported wholesale poultry derived demand: $E Q_{Y e}^{w}-\eta_{Y e}^{w} E P_{Y}^{w}=E Z_{Y e}^{w}$.

Balagtas and Kim (2007) note this model can be expressed in matrix form as $\mathbf{R Y}=\mathbf{Z}$, where $\mathbf{R}$ is a matrix of model parameters (i.e., elasticities), $\mathbf{Y}$ is a column vector of endogenous changes in prices and quantities relative to an initial equilibrium, and $\mathbf{Z}$ is a column vector of percentage changes associated with vaccination protocol adoption. The model defines proportional changes in equilibrium prices and quantities for each evaluated market level and species in response to exogenous changes corresponding to vaccination introduction. These proportional changes are identified as:

(26) $\mathbf{Y}=\mathbf{R}^{-1} \mathbf{Z}$.

We use producer surplus to quantify the net economic impact of vaccination adoption. Changes in producer surplus created by introducing vaccinations can be calculated in terms of changes in prices and quantities identified by the EDM as:

$$
\Delta P S_{a}^{m}=P_{a}^{m} Q_{a}^{m}\left(E P_{a}^{m}+E W_{a}^{m}\right)\left(1+0.5 E Q_{a}^{m}\right)
$$

where producer surplus is denoted by PS (Lusk and Anderson 2004). The superscript $m$ denotes the market level (i.e., $r=$ retail, $w=$ wholesale (processor/packer), $s=$ fed cattle (feeding), and $f=$ feeder (farm level)) and subscript $a$ denotes the industry/species evaluated (i.e., beef, pork, or poultry). Change in total producer surplus is the sum of the change in producer surplus from each market level for a species, $\triangle P S_{a}=\sum_{m} \Delta P S_{a}^{m}$.

Solutions to equation (26) require elasticity estimates for the matrix of parameters $(\boldsymbol{R})$. Identifying these estimates by econometrically estimating structural supply and demand equations for the 25-equation EDM is problematic. As in most EDM applications, direct estimation of elasticities is prohibited by the large number of equations and by identification problems in jointly estimating supply and demand relationships (Brester et al. 2004). However, given the $E$. coli vaccination results in relatively small aggregate market shifts (in proportional terms), we follow standard EDM procedures and utilize elasticity estimates reported in the published literature.

We simulate our model annually for ten consecutive years to allow for adoption over time by producers of the $E$. coli vaccination technology. Consistent with historical beef cattle cycles, we assume that it takes the marketplace ten years to fully adjust from short-run to long-run relationships. Ten years of market effects were simulated by linearly adjusting all elasticities between short-run (year 1) and long-run (year 10) using elasticity estimates employed by Pendell et al. (2010) ${ }^{\mathrm{f}}$. The supply, demand, and quantity transmission elasticities used are equivalent to those used by Schroeder and Tonsor (2011). Similarly, base price and quantity values are necessary to estimate surplus 
calculations. The market price and quantity values are annual average values for calendar year 2012 as reported by the Livestock Marketing Information Center (LMIC).

Our analysis assumes $10 \%$ of fed cattle are vaccinated in year 1, 25\% in year 2, 50\% in year 3, and $90 \%$ in years $4-10$. This reflects a typical "S-curve" adoption pattern where adoption increases rapidly upon introduction of the technology with a plateau corresponding to the fact that few technologies are every completely adopted by all parties in a heterogeneous industry.

\section{Competing interests}

The authors declare that they have no competing interests.

\section{Acknowledgements}

Partial funding assistance is acknowledged from the federal-State Marketing Improvement Programs USDA and the USDA STEC CAP grant.

Received: 14 March 2014 Accepted: 5 December 2014

Published online: 29 January 2015

\section{References}

AgManager.Info. 2013. Livestock \& Meat Marketing: Meat Demand Tables, Charts, and Videos. Available at: http://www. agmanager.info/livestock/marketing/Beef\%20Demand/default.asp

Antle JM (1999) Benefits and costs of food safety regulation. Food Policy 24:605-623

Antle JM (2000) No such thing as a free safe lunch: the cost of food safety regulation in the meat industry. Am J Agric Econ 82:310-322

Bailey D (2007) Political economy of the U.S. Cattle and beef industry: innovation adoption and implications for the future. J Agric Resour Econ 32:403-416

Balagtas JV, Kim S (2007) Measuring the effects of generic dairy advertising in a multi-market equilibrium. Am J Agric Econ 89:932-946

Blasi D, Brester G, Crosby C, Dhuyvetter K, Freeborn J, Pendell D, Schroeder T, Smith G, Stroade J, Tonsor G (2009) Benefit-Cost Analysis of the National Animal Identification System, Final Report submitted to USDA-APHIS on January 14, 2009., Available at: http://www.naiber.org/Publications/NAIBER/BC.analysis.NAIS.pdf (accessed August 5, 2013)

Brester GW, Marsh JM, Atwood JA (2004) Distributional impacts of country-of-origin labeling in the U.S. Meat industry. J Agric Resour Econ 29:206-227

Callaway TR, Edrington TS, Loneragan GH, Carr MA, Nisbet DJ (2013) Review: current and near-market intervention strategies for reducing Shiga toxin-producing Escherichia coli (STEC) shedding in cattle. Agric Food Anal Bacteriol 3:103-120

Cull CA, Paddock ZD, Nagaraja TG, Bello NM, Babcock AH, Renter DG (2012) Efficacy of a vaccine and direct-Fed microbial against fecal shedding of escherichia coli 0157:H7 in a randomized Pen-level field trial of commercial feedlot cattle. Vacccine 30:6210-6215

Dodd CC, Sanderson MW, Jacob ME, Renter DG (2011) Modeling preharvest and harvest interventions for escherichia coli 0157 contamination of beef cattle carcasses. J Food Prot 74(9):1422-1433

Ferrier PM, Buzby JC (2013) The economic efficiency of sampling size: the case of beef trim. Risk Anal 33:368-384

Gabbett RJ (2010) "Cargill Settles E. coli Lawsuit with Stephanie Smith." Meatingplace.com. May 13., Available at: http://www.meatingplace.com/Industry/News/Details/16513

Hurd HS, Malladi H (2012) "An outcomes model to evaluate risks and benefits of escherichia coli vaccination in beef cattle.". Foodborne Pathog Dis 9(10):952-961

Livestock Marketing Information Center. 2013. Available at: http://www.Imic.info/.

Lueger A, Schroeder TC, Renter DG (2012) "Feedlot Costs of Vaccinating Cattle for E.coli." K-State Department of Agricultural Economics. Publication: TCS-December 2012., Available at: http://www.agmanager.info/livestock/budgets/production/ beef/TCS_FactSheet_EcoliVaccination_12-07-12.pdf. Accessed on December 2, 2013

Lusk JL, Anderson JD (2004) Effects of country-of-origin labeling on meat producers and consumers. J Agric Resour Econ 29:185-205

Marsh TL, Schroeder TC, Mintert J (2004) "Impacts of meat product recalls on consumer demand in the USA," Appl Econ 36:897-909

Matthews L, Reeve R, Gally DL, Low JC, Woolhouse MEJ, McAteer SP, Locking ME, Chase-Topping ME, Haydon DT, Allison LJ, Hanson MF, Gunn GJ, Reid SWJ (2013) "Predicting the public health benefit of vaccinating cattle against Escherichia coli O157.". Proc Natl Acad Sci U S A 110:16265-162770, Available at: www.pnas.org/cgi/doi/10.1073/ pnas. 1304978110

Moghadam AK, Schmidt C, Grier K (2013) The impact of E.Coli 0157:H7 recalls on live cattle futures prices: revisited. Food Policy 42:81-87

Pendell D, Brester G, Schroeder T, Dhuyvetter K, Tonsor GT (2010) Animal identification and tracing in the United States. Am J Agric Econ 92:927-940

Pendell DL, Tonsor GT, Dhuyvetter KC, Brester GW, Schroeder TC (2013) Evolving U.S. Beef Export Market Access Requirements for Age and Source Verification." Food Policy. Available at: http://www.sciencedirect.com/science/ article/pii/S030691921300064X\#

Perry B, Marsh TL, Jones R, Sanderson MW, Sargeant JM, Griffin DD, Smith RA (2007) "Joint product management strategies on E. Coli 0157 and feedlot profits,". Food Policy 32:544-565 
Piggott NE, Marsh TL (2004) "Does food safety information impact US meat demand?". Am J Agric Econ 86:154-174 Scallan E, Hoekstra RM, Angulo FJ, Tauxe RV, Widdowson M-A, Roy SL, Jones JL, Griffin PL (2011) Foodborne illness acquired in the United States-major pathogens. Emerg Infect Dis 17:7-15

Scharff RL (2010) Health-Related Costs from Foodborne Illness in the United States." Produce Safety Project. Georgetown University. Available at: http://www.pewhealth.org/reports-analysis/reports/health-related-costs-from-foodborne-illnessin-the-united-states-85899367904

Schroeder TC, Tonsor GT (2011) Economic impacts of zilmax $x^{\oplus}$ adoption in cattle feeding. J Agric Resour Econ 36:521-535

Scott C (2012) "Maple Leaf Foods Distributes Listeriosis Settlement Checks." Meatingplace.com. February 7. Available at: http://www.meatingplace.com/Industry/News/Details/30497

Smith GG, Goebel SE, Culbert CR, Guilbault LA (2013a) Reducing the public health risk of escherichia coli O157 exposure by immunization of cattle. Can J Public Health 104:e9-e11, Available at: http:/www.ncbi.nlm.nih.gov/ pubmed/23618124

Smith BA, Fazil A, Lammerding AM (2013b) A risk assessment model for escherichia coli O157:H7 in ground beef and beef cuts in Canada: evaluating the effects of interventions. Food Control 29:364-381

Snedeker KG, Campbell M, Sargeant JM (2012) A systematic review of vaccinations to reduce the shedding of Escherichia coli $\mathrm{O} 157$ in the faeces of domestic ruminants. Zoonoses Public Health 59:126-138

Thomson DU, Loneragan GH, Thornton AB, Lechtenberg KF, Emery DA, Burkhardt DT, Nagaraja TG (2009) "Use of a sidephore receptor and porin proteins-based vaccine to control the burden of escherichia coli 0157:H7 in feedlot cattle." Foodborne Pathog Dis 6(7):871-877

Tonsor GT, Mintert J, Schroeder TC (2010) "U.S. Meat demand: household dynamics and media information impacts." J Agric Resour Econ 35:1-17

U.S. Department of Agriculture, Economic Research Service. 2010. "Foodborne Illness Cost Calculator: STEC O157:H7." Available at: http://www.ers.usda.gov/Data/FoodBornelllness/ecoli intro.asp

Varela NP, Dick P, Wilson J (2013) Assessing the existing information on the efficacy of bovine vaccination against Escherichia coli O157:H7 - a systematic review and meta-analysis. Zoonoses Public Health 60:253-268

Vogstad AR, Moxley RA, Erickson GE, Klopfenstein TJ, Smith DR (2013) Assessment of heterogeneity of efficacy of a three-dose regimen of a type III secreted protein vaccine for reducing STEC 0157 in feces of feedlot cattle. Foodborne Pathog Dis 10:678-683

Weise E (2011) "Who Should Pay to Make Ground Beef Safe from E. coli?" In: USA Today, November 28. Available at: http://usatoday30.usatoday.com/money/industries/food/story/2011-12-01/safe-meat/51447546/1

Wohlgenant, Michael K (1993) Distribution of Gains from Research and Promotion in Multi-Stage Production Systems: The Case of the U.S. Beef and Pork Industries. American Journal of Agricultural Economics 75(3):642-51.

Zingg A, Siegrist M (2012) People's willingness to eat meat from animals vaccinated against epidemics. Food Policy 37(3):226-231.

\section{Submit your manuscript to a SpringerOpen ${ }^{\circ}$} journal and benefit from:

- Convenient online submission

- Rigorous peer review

- Immediate publication on acceptance

- Open access: articles freely available online

- High visibility within the field

- Retaining the copyright to your article 